\title{
Colorectal Cancer Causes and Treatments: A Minireview
}

\author{
Anita Nasrallah and Mirvat El- Sibai*
}

Department of Natural Sciences, Lebanese American University, Beirut 1102 2801, Lebanon

\begin{abstract}
Colon cancer is the cancer of the epithelial cells lining the colon. This type of cancer occurs in many people that are either genetically predisposed or exposed to risk factors. Colorectal cancer is mainly divided into different stages according to invasiveness and metastatic ability of the tumor. Many mutations are acquired, leading to this malignancy. Treatment of colorectal cancer range from surgery in early stages to palliative care in most advanced stages. In this minireview, we summarize the latest findings on colorectal cancer.
\end{abstract}

Keywords: Colon cancer, Oncogenes, Apoptotic proteins, genetics, Inflammatory Bowel Diseases, Crohn's disease.

Colorectal cancer, commonly known as bowel cancer, occurs in the colon, rectum, or appendix. Genetic analysis shows that tumors in these three locations are genetically of the same cancer [1]. Colorectal cancer is the second most commonly diagnosed cancer in females, the third in males [2], and the forth around the world [3]. More than a million cases are yearly detected globally [4]. It is widespread in developed countries, where around $60 \%$ of the cases were diagnosed [5], most of which lead to death [6].

There are several causes for the onset of colorectal cancers, which are nowadays better diagnosed and classified according to several criteria. Consistently, different treatments and prognostic measures are currently used to try and successfully cure this type of cancer [4].

\section{CAUSES AND PREDISPOSITION}

Colorectal cancer occurs in a wide range of people. Most of them were previously, and might still be exposed to numerous risk factors. The rest are either genetically predisposed, or associated with other bowel diseases.

\section{Risk Factors}

It is estimated that more than $80 \%$ of patients with colorectal cancer were exposed to a number of risk factors, such as male gender, older age [4], high intake of red meat or fat, smoking and obesity [7]. The risk of alcohol increases at more than a drink per day [8]. Also, around $10 \%$ of these cases are related to insufficient activity [9].

\section{Genetics}

Around $18 \%$ of all cases are patients with a family history. Thus, they have a two to three-fold risk increase than other people. Furthermore, three main genetic diseases are

\footnotetext{
*Address correspondence to this author at the Department of Natural Sciences, Lebanese American University, P.O. Box: 13-5053. Chouran 1102 2801, Beirut, Lebanon; Tel: +961-1-786456; Ext: 1253;

Fax:+961-1-867098; E-mail: mirvat.elsibai@lau.edu.lb
}

well associated with this type of cancer. The most common is known as the Lynch syndrome, or the hereditary nonpolyposis colorectal cancer (HNPCC) [4]. Familial adenomatous polyposis (FAP) [10] and Gardner syndrome [11] are both as well strongly associated with this type of cancer.

\section{Inflammatory Bowel Diseases}

A third cause is the incidence of the Inflammatory Bowel Diseases, such as ulcerative colitis and Crohn's disease [12]. The longer the onset of these diseases [13], and the worse the inflammation [14] will directly affect the risk of having colorectal cancer. However, only about $2 \%$ of this cancer is associated with the previously mentioned diseases [12].

\section{PATHOGENESIS}

Colorectal cancer originates from the epithelial lining, most often as a consequence of mutations in the Wnt signaling pathway. These mutations can be either acquired or inherited. They mostly occur in the intestinal gland stem cells [15].

\section{Tumor Suppressor Genes}

In all colorectal cancer, $A P C$ is the most commonly mutated gene. It produces the APC protein, which prevents the accumulation of the $\beta$-catenin protein by binding to and degrading it. In the absence of APC protein, $\beta$-catenin highly accumulates in the cytoplasm, translocates to the nucleus, and binds to DNA, thus activating the transcription of several genes. These genes are responsible for stem cell renewal and differentiation. However, when improperly expressed at elevated levels they cause cancer [16].

Some colorectal cancers have high $\beta$-catenin levels due to mutations in its gene $C T N N B 1$, and not in the $A P C$ gene. These mutations block the degradation of $\beta$-catenin. Other colorectal cancers have mutations in other APC analogues, such as NKD1, TCF7L2, AXIN1, or AXIN2. Another tumor suppressor, PTEN, normally inhibits the overexpressed 
oncogene PI3K. However if PTEN is mutated, it becomes deactivated [16].

\section{Apoptotic Proteins}

Other than the defects mentioned above, additional mutations must take place for the cells to acquire more cancerous characteristics. One of these mutations occurs in the p53 protein, which is produced by the TP53 gene. This apoptotic protein monitors normal cell division. It kills the cells if they acquire any defect in the Wnt signaling pathway. Its mutation will change the tissue from a non-invasive adenoma into an invasive carcinoma [17]. In some cases, the gene encoding for BAX, another protective protein, is mutated, instead of the TP53 gene [16].

Other apoptotic proteins are frequently mutated and deactivated in colorectal cancers. A major protein is the TGF- $\beta$, which in at least half of colorectal cancers has a deactivating mutation. In some cases, TGF- $\beta$ is not the protein mutated, but its downstream protein SMAD (16). Another protein is the DCC protein, or Deleted in Colorectal Cancer. It acquires a deletion of its chromosomal segment [18].

\section{Oncogenes}

Normal genes that encode proteins, known as oncoproteins, responsible for the regulation of cell growth and differentiation are known as proto-oncogenes. They are mainly involved in signal transduction. When activated, increased expression or mutations will result in the transformation into oncogenes, which are tumor-inducing agents [19]. These are overexpressed in colorectal cancer, such as genes encoding the proteins PI3K, RAF, and RAS [20].

Under normal conditions and in response to growth factors, these proteins will stimulate the cell to divide. Acquired mutations will lead to the over-activation of cell proliferation. In some cases, the chronological order of mutations is crucial for the progression of cancer. To illustrate, if at first a KRAS mutation occurred, this will lead to a self-limiting borderline lesion. On the other hand, if the KRAS mutation occurs after an APC mutation, it often leads to cancer [21].

All the previously discussed mutations occur in one type of colorectal carcinomas, known as the hypermutated tumor type. These tumors have mutated forms of $B R A F, T C F 7 L 2$, SLC9A9, MSH3, MSH6, TGFBR2, and ACVR2A. Genomescale analysis reveals that the non-hypermutated tumor type contains mutated ARIDIA, ATM, SOX9, and FAM123B. What is in common among the genes in both carcinomas is their involvement in the TGF- $\beta$ and WNT signaling pathways. This, in turn, will result in the hyper activity of the central player in colorectal cancer, MYC [1].

\section{CLASSIFICATION OF COLORECTAL CANCER}

The most widely used classification system is the TNM Staging System. It is considered the most descriptive and precise. $\mathrm{T}$ stands for the depth of the tumor, and to which level did it penetrate the colon wall. $\mathrm{N}$ refers to the involvement of lymph nodes. $M$ stands for the degree of metastases that took place or whether the tumor has spread or not [22].

Another less used system is the Duke's system [23]. It was then modified and became the Modified Dukes Staging System. This system classifies the tumors under four main categories, i.e. A, B, C, and D. Modified Duke Stage A is the tumors that only reach the mucosal wall. B is the ones that penetrate through and out of the wall. $\mathrm{C}$ is the advancement of the tumor into the lymph nodes. D is when tumors are depicted in other organs, such as the liver, lung and bone [24].

\section{SYMPTOMS AND DIAGNOSIS}

Signs and symptoms of colorectal cancer greatly depend on its location and ability to metastasize. These include fever, loss of appetite, weight loss, constipation, and blood in stool. In people older than fifty, common symptoms are nausea, vomiting anaemia, and rectal bleeding [25]. It is important to note that the most evident symptoms are weight loss and rectal bleeding [26]. Without them all other symptoms can be indicative of several different gastrointestinal diseases [27].

Colorectal cancers occurring on the right side of the colon, i.e. the ascending colon and cecum, usually cause severe fecal obstruction and anaemia. This is because these tumors tend to grow outward from a location of the bowel wall. However, left-sided tumors, i.e. tumors of the descending colon, cause constipation. These tumors are most likely circumferential [28].

The first step towards diagnosis is to take tumor biopsy during wither colonoscopy or sigmoidoscopy. After confirming the presence of the cancer, imaging tests are performed of the patient's chest, abdomen and pelvis, to determine the extent of the disease. These tests include CT scan, PET, and MRI. Based on these results, the physician can establish a clear idea of the stages of the cancer, depending on the TNM system of classification [4].

\section{PATHOLOGY OF THE TUMOR}

After biopsy or surgery, a pathology report explicitly determines the cell type and grade of the tumor. In 95\% of the cases, the colon cancer type is adenocarcinoma [29]. It originates from the glandular epithelium, invading the wall and infiltrating all layers. Tumor cells have irregular structures and might secrete mucus. Depending on the predominant cellular pleomorphism, gland architecture, and secretion of mucus, adenocarcinoma is separated into three differentiation levels: poorly, moderately, and well differentiated. Other than adenocarcinoma, rare types of colorectal cancer include squamous cell carcinoma and lymphoma [30].

Besides, the majority of colorectal cancer tumors are cyclooxygenase- 2 , or COX-2, positive. This enzyme is abundantly found in cancerous tissue of the colon. It aids in abnormal cell growth [31]. 


\section{TREATMENT AND PROGNOSIS}

As any other type of cancer, the treatment of colorectal cancer depends on its advancement. At early stages, surgery is mostly curative. At later stages when the cancer is metastatic, physicians tend to treat their patients by trying to prolong their life and keep them comfortable [32].

\section{Surgery}

Patients with localized colorectal cancer undergo surgeries to extract the tumor. It is either done by laparotomy or laparoscopy, which is a minimally invasive procedure. If other tumors are metastasized to the lungs or liver, they are removed surgically [4].

\section{Chemotherapy}

In some cases, chemotherapy is used before surgery. This will help shrink the tumor before eradicating it. In other cases where the cancer has metastasized and entered the lymph nodes, chemotherapy is a must to help increase the life expectancy of the patient. Drugs may include oxaliplatin, irinotecan, leucovorin, UFT, capecitabine, or 5-fluorouracil. Monoclonal antibodies against molecular targets include cetuximab, panitumumab, or bevazicumab [33]. Understanding better the tumor biology and molecular pathways and mechanisms effectively led to the discovery of novel agents that specifically target molecular elements of cancer cells. This has helped improving the efficacy of drugbased chemotherapy that is nowadays combined with targeted monoclonal antibodies. Research is being extensively done to try and use cell signaling pathways as targets for colorectal cancer treatment, even though these pathways highly intercorrelate and crosstalk [34].

\section{Radiation}

Combining chemotherapy and radiation might be helpful. But, in most cases, this is not used as curative technique, since the bowels are highly sensitive to radiation [35].

\section{Palliative Care}

At the stage when colorectal cancer becomes incurable, the best remedy is to improve the quality of life by alleviating the symptoms and reducing the complications [36]. These procedures may include stent placement or bypassing part of the intestine, and pain medications. This will help reduce bleeding, intestinal obstruction, and abdominal pain [37].

Survival rates are directly linked to the type of cancer and its detection. Late stage cancers have five times less survival rates that early stage ones [38]. To be on a safe side, followup is highly mandatory. This will help diagnose any new tumors that develop later, but had not originated from the original tumor [39]. Physical examinations are recommended, as well as blood tests and CT scans [40]. Close follow-up and intensive surveillance can reduce the five-year mortality rate of patients with colorectal cancer from $37 \%$ to $30 \%[41,42]$.

\section{PREVENTION}

The most important ways to prevent colorectal cancer are a healthy lifestyle, appropriate medication, and continuous screening.

\section{Life Style}

Dietary recommendations include reducing the consumption of red meat and increasing the intake of fruits, vegetables, fibers and whole grains [43]. Physical activity also helps reducing the risk of colorectal cancer [44].

\section{Medication}

People at high risk of having colorectal cancer are advised to take aspirin and celecoxib. They both appear to decrease the risk factor. Nevertheless, these drugs are not recommended to those at average risk [45]. Vitamin D, especially its blood concentration, and Calcium intake are also associated with lower risks of colorectal cancer [46, 47].

\section{Screening}

Several screening methods are applied nowadays, and they proved to be helpful in reducing death by the early detection [48]. The three main tests are fecal occult blood testing of the stool, sigmoidoscopy, and colonoscopy [49]. The newest screening method is the M2-PK test to stool samples. The M2-PK enzyme biomarker is highly sensitive to colorectal cancer. It is able to detect bleeding and nonbleeding types, which a fecal occult blood test cannot do [50].

\section{CONFLICT OF INTEREST}

The authors confirm that this article content has no conflicts of interest.

\section{ACKNOWLEDGEMENT OF FUNDING}

The department of Natural science, the Lebanese American University.

\section{REFERENCES}

[1] Cancer Genome Atlas Network. Comprehensive molecular characterization of human colon and rectal cancer. Nature 2012; 487(7407): 330-7.

[2] World Health Organization. World Health Organization. [Online].; 2010. Available from: http://www.who.int/cancer/detection/colorectalcancer/en/

[3] Jemal A, Bray F, Center MM, Ward E, Forman D. Global cancer statistics. Cancer J Clin 2011; 61(2): 69-90.

[4] Cunningham D, Atkin W, Lenz HJ, et al. Colorectal cancer. Lancet 2010; 375(9719): 1030-47.

[5] Ferlay J, Shim HR, Bray F, Forman D, Mathers C, Parkin DM. Estimates of worldwide burden of cancer in 2008: GLOBOCAN 2008. Int J Cancer 2010; 127(1): 2893-917.

[6] Merika E, Saif MW, Katz A, Syrigos C, Morse M. Colon cancer vaccines: an update. In vivo 2010; 24(5): 607-28.

[7] Watson AJ, Collins PD. Colon cancer: a civilization disorder. Digest Dis 2011; 29(2): 222-8.

[8] Fedirko V, Tramacere I, Bagnardi V, et al. Alcohol drinking and colorectal cancer risk: an overall and dose-response meta-analysis of published studies. Ann Oncol 2011; 22(9): 1958-72.

[9] Lee IM, Shiroma EJ, Lobelo F, et al. Effect of physical inactivity on major non-communicable diseases worldwide: an analysis of 
burden of disease and life expectancy. Lancet 2012; 380(9838): 219-29.

[10] Half E, Bercovich D, Rozen P. Familial adenomatous polyposis. Orphanet J Rare Dis 2009; 4(22): doi: 10.1186/1750-1172-4-22.

[11] Juhn E, Khachemoune A. Gardner syndrome: skin manifestations, differential diagnosis and management. Am J Clin Dermatol 2010; 11(2): 117-22

[12] Jawad N, Direkzen N, Leedham SJ. Inflammatory bowel disease and colon cancer. Recent Res Cancer Res 2011; 185(1): 99-115.

[13] Xie J, Itzkowitz SH. Cancer in inflammatory bowel disease. World J Gastroenterol 2008; 14(3): 378-89.

[14] Triantafillidis JK, Nasioulas G, Kosmidids PA. Colorectal cancer and inflammatory bowel disease: epidemiology, risk factors, mechanisms of carcinogenesis and prevention strategies. Anticancer Res 2009; 29(7): 2727-37.

[15] Ionov Y, Peinado MA, Malkhosyan S, Shibata D, Perucho M. Ubiquitous somatic mutations in simple repeated sequences reveal a new mechanism for colonic carcinogenesis. Nature 1993; 363(6429): 558-61.

[16] Markowitz SD, Bertagnolli MM. Molecular origins of cancer: molecular basis of colorectal cancer. N Engl J Med 2009; 361(25): 2449-60.

[17] Chakravarthi S, Krishnan B, Madhavan M. Apoptosis and expression of p53 in colorectal neoplasms. Indian J Med Res 1999; 86(7): 95-102.

[18] Mehlen P, Fearon ER. Role of the dependence receptor DCC in colorectal cancer pathogenesis. J Clin Oncol 2004; 22(16): 342028.

[19] Chial H. Proto-oncogenes to oncogenes to cancer. Nat Educ 2008; 1(1): 177.

[20] Todd R, Wong DT. Oncogenes. Anticancer Res 1999; 19(6A): 4729-46.

[21] Vogelstein B, Kinzler KW. Cancer genes and the pathways they control. Nat Med 2004; 10(8): 789-99.

[22] Yarbro JW, Page DL, Fiedling PL, Partridge EE, Murphy GP. American joint committee on cancer prognostic factors consensus conference. Cancer 1999; 86(11): 2436-46.

[23] Dukes CE. The classification of cancer of the rectum. J Pathol Bacteriol 1932; 35(3): 323-32.

[24] Astler VB, Coller FA. The prognostic significance of direct extension of carcinoma of the colon and rectum. Ann Surg 1954; 139(6): 846-51.

[25] Alpers DH, Kalloo AN, Owyang C, Powell DW, Kaplowitz N. Principles of clinical gastroenterology. In: Yamad T, Alpers DH, Kalloo AN, Powell DW Eds. Principles of Clinical Gastroenterology. 5th ed.: Wiley; 2009. pp. 380-2.

[26] Astin M, Griffin T, Neal RD, Rose P, Hamilton W. The diagnostic value of symptoms for colorectal cancer in primary care: a systematic review. Br J Gen Pract 2011; 61(586): p. 231-43.

[27] Adelstein BA, Macaskil P, Chan SF, Katelaris PH, Irwig L. Most bowel cancer symptoms do not indicate colorectal cancer and polyps: a systematic review. BMC Gastroenterol 2011; 11(65): $1-10$.

[28] Jellema P, van der Windt DA, Bruinvels DJ, et al. Value of symptoms and additional diagnostic tests for colorectal cancer in primary care: systematic review and meta-analysis. Br Med J 2010; 340(1269): 1-21.

[29] Bafandeh Y, Khoshbaten M, Eftekhar Sadat AT, Farhanq S. Clinical predictors of colorectal polyps and carcinoma in a low prevalence region: results of a colonoscopy based study. World J Gastroenterol 2008; 14(10): 1534-8.

[30] Danciu M, Mihailovici MS. Atlas of Pathology. [Online].; 2010. Available from: http://www.pathologyatlas.ro/
[31] Tsujii M, Kawano S, Tsujii S, Sawaoka H, Hori M, Dubois RN. Cyclooxygenase regulates angiogenesis induced by colon cancer Cells. Cell 1998; 93(5): 705-16.

[32] Stein A, Atanackovic D, Bokemeyer C. Current standards and new trends in the primary treatment of colorectal cancer. Eur J Cancer 2011; 47(3): S312-4.

[33] Hoyle M, Crathorne L, Peters J, et al. The clinical effectiveness and cost-effectiveness of cetuximab (mono- or combination chemotherapy), bevacizumab (combination with non-oxaliplatin chemotherapy) and panitumumab (monotherapy) for the treatment of metastatic colorectal cancer after first-lin. Health Technol Assess 2013; 17(14): 1-237.

[34] Chung HH, Jang BI. A perspective role of targeted therapy in colon cancer. Korean J Gastroenterol 2013; 61(3): 128-35.

[35] Devita VT, Lawrence TS, Rosenberg SA. DeVita, Hellman, and Rosenberg's Cancer: principles and practice of oncology Philadelphia: Lippincott Williams \& Wilkins, a Walters Kluwer Busines 2008.

[36] Wasserberg N, Kaufman HS. Palliation of colorectal cancer. Surg Oncol 2007; 16(4): 299-310.

[37] Amersi F, Stamos MJ, Ko CY. Palliative care for colorectal cancer. Surg Oncol Clin N Am 2004; 13(3): 467-77.

[38] Lin Koo S, Wen JH, Hillmer A, Cheah PY, Tan P, Tan IB. Current and emerging surveillance strategies to expand the window of opportunity for curative treatment after surgery in colorectal cancer. Expert Rev Anticancer Ther 2013; 13(4): 439-50.

[39] Simmonds PC, Primrose JN, Colquitt JL, Garden OJ, Poston GJ, Rees M. Surgical resection of hepatic metastases from colorectal cancer: a systematic review of published studies. Br J Cancer 2006; 94(7): 982-99.

[40] Desch CE, Benson AB, Somerfield MR, et al. Colorectal cancer surveillance: 2005 update of an American Society of Clinical Oncology practice guideline. J Clin Oncol 2005; 23(33): 8512-9.

[41] Figueredo A, Rumble BR, Maroun J, et al. Follow-up of patients with curatively resected colorectal cancer: a practice guideline. BMC Cancer 2003; 3(26): 1-23.

[42] Renehan AG, Egger M, Saunders MP, O'Dwyer ST. Impact on survival of intensive follow up after curative resection for colorectal cancer: systematic review and meta-analysis of randomised trials. Br Med J 2002; 324(7341): 813-20.

[43] Doyle VC. Nutrition and colorectal cancer risk: a literature review. Gastroenterol Nurs 2007; 30(3): 178-82.

[44] Harriss DJ, Atkinson G, Batterham A, et al. Lifestyle factors and colorectal cancer risk (2): a systematic review and meta-analysis of associations with leisure-time physical activity. Colorectal Dis 2009; 11(7): 689-701.

[45] Cooper K, Squires H, Carroll C, et al. Chemoprevention of colorectal cancer: systematic review and economic evaluation. Health Technol Assess 2010; 1-206.

[46] Ma Y, Zhang P, Wang F, Yang J, Liu Z, Qin H. Association between vitamin $\mathrm{D}$ and risk of colorectal cancer: a systematic review of prospective studies. J Clin Oncol 2011; 29(28): 3775-82.

[47] Yin L, Grandi N, Raum E, Haug U, Arndt V, Brenner H. Metaanalysis: Serum vitamin D and colorectal adenoma risk. Prev Med 2011; 53(1-2): 10-16.

[48] He J, Efron JE. Screening for colorectal cancer. Adv Surg 2011; 45: 31-44.

[49] Qaseem A, Denberg TD, Hopkins RH, et al. Screening for colorectal cancer: a guidance statement from the American College of Physicians. Ann Intern Med 2012; 156(5): 378-86.

[50] Tonus C, Sellinger M, Koss K, Neupert G. Faecal pyruvate kinase isoenzyme type M2 for colorectal cancer screening: a metaanalysis. World J Gastroenterol 2012; 18(30): 4004-11. 